Arch. Met. Geoph. Biokl., Ser. B, 19, 325-338 (1971)

(C) by Springer-Verlag 1971

Department of Geography, The University of Michigan, Ann Arbor, Michigan, U.S.A.

\title{
The Climatonomy of a Needle Ice Event: An Experiment in Simulation Climatology
}

\author{
Sam I. Outcalt
}

With 3 Figures

Received March 19, 1971

\section{Summary}

Soil surface temperature, net radiation and surface heave are used to evaluate a computer simulation of a needle ice event at Vancouver, Canada. The simulation which includes fusion and soil water flow effects, provides a working example of a simulation-sensitivity experiment in climatology and therefore has implications which transcend the rather restricted subject of diurnal soil frost effects.

\section{Zusammenfassung}

Die Klimatonomie der Eisnadelbildung: Experimente mit einem klimatologischen Modell

Die Temperatur der Bodenoberfläche, die Strahlungsbilanz und die Bodenbewegung werden in einem Rechenmodell benützt, das die Eisnadelbildung in Vancouver, Kanada, simuliert. Das Modell, welches den Gefriervorgang und den Effekt der Wasserströmung im Boden einbezieht, stellt ein Beispiel eines Simulations- und Sensitivitätsexperiments in der Klimatologie dar, welches über die Belange des beschränkten Sachgebietes der Bodenfrosteffekte hinausgeht.

\section{Introduction}

Needle ice is the product of ice segregation near the soil surface. Ice segregation is the increase in the water (ice) volume fraction of a soil layer produced by the upward migration of soil water to the freezing plane during diurnal frost events. The growth and prediction of neddle ice is of considerable interest to soil and plant scientists due to the plant damage which is often the result of needle 
growth and ablation (melting). The process is discussed in detail by Outcalt $[6,7,8]$.

Climatonomy has been described by Letrau [3] as indicating " ... a study of man's physical environment that is significantly more numerically and theoretically oriented than conventional climatology".

\section{The Task}

The task discussed here is the numerical simulation of a geomorphological event (i. e. frost heave). Specifically, the mathematical representation of the gross processes of energy and mass transfer during a diurnal needle ice growth-melt cycle using the time dependence of soil heave (needle height) and the surface temperature regime to evaluate the quality of the simulation. In short, can a climatic-geomorphic event be adequately simulated using a series of equations which portray the gross features of energy and mass transfer within the soil-atmospheric system?

Further, having been satisfied with the outcome of the initial simulation task, the response sensitivity of needle growth to the manipulation of meteorological and terrestial environmental boundary conditions can be simulated and compared with observation. Success in this effort permits investigators in fields limited by the methodological restrictions of historical data such as climatology to approach the sophistication of controlled laboratory experimentation common in the "pure sciences".

\section{Background}

Ground frost conditions have been observed as part of the agrometeorological programme at the University of British Columbia for over ten years. During the latter portion of this period that record and diurnal micrometeorological observations provide a considerable body of knowledge concerning the physical environment of needle ice events $[1,7]$. These data form the body of information which was used to set the boundary conditions and test the output functions (e.g. soil heave, soil surface temperature) in the simulation experiment.

\section{The Simulator}

This author has modified his general surface climate simulator which was an extension of Myrup's work [5,9] for the needle ice case. This approach was selected in preference to the scheme of 
LONNQVIST [4] as it is based entirely upon equilibrium temperature theory and does not require the intervention of transfer functions operating on input and output functions represented as Fourier series. Further, the equilibrium temperature approach has been formerly utilized by this author to explain the variability of diurnal frozen soil structures at a wet site [6]. Lastly, it is relatively easy to introduce the effects of sub-surface soil water fusion and melt into the fabric of the numerical simulator as needle ice usually forms beneath a $1-2 \mathrm{~cm}$ cap of hard frozen soil in which the soil water has been frozen in situ. The exact modifications to the general surface climate simulator are discussed in detail. For the background information on general equilibrium temperature simulation the reader is referred to Myrup [5] and a recent paper by OutCalt [9].

\section{Simulator Modifications for the Needle Ice Case}

The general surface climate simulator was designed to approximate the heat transfer environment in a homogeneous soil. However, past studies at the University of British Columbia site indicated that thermally driven soil water and fusion (ice formation-melt) have a pronounced effect on the soil thermal regime. The effects produced by these processes were incorporated in the model as follows:

\subsection{Heat Transfer by Soil Water Movement}

The nocturnal increase in enthalpy (heat content) at the $3 \mathrm{~cm}$ soil level due to water flow from the warmer lower layers was simulated by the addition of a second term to the Fickian diffusion equation which was solved using finite difference methods [10]. This equation is presented in its differential form and illustrates the effects on temperature $(T)$ through time $(t)$ producend by diffusivity $(\alpha)$, depth $(Z)$, soil water velocity $(U)$ and the ratio of the volumetric heat capacity of water to that of the soil $\left(C_{w} / C_{s}\right)$ :

$$
\partial T / \partial t=\alpha\left(\partial^{2} T / \partial Z^{2}\right)+U(C w / C s)(\partial T / \partial Z) .
$$

Field studies at Vancouver.indicated that the velocity of water flow (not flux) was in the realm of $2 \mathrm{~cm} / \mathrm{hr}$ [7]. As the diurnal damping depth controlled the soil temperature computation levels the finite difference form of Eq. (1) was used to correct the temperature at the uppermost soil substrate level at each computation. 


\subsection{Needle Growth and Ablation}

Needle growth-ablation has two major effects. It alters the regime of heat flow to the soil surface and produces a vertical displacement of the soil surface (heave). The needle ice generator (the addition to

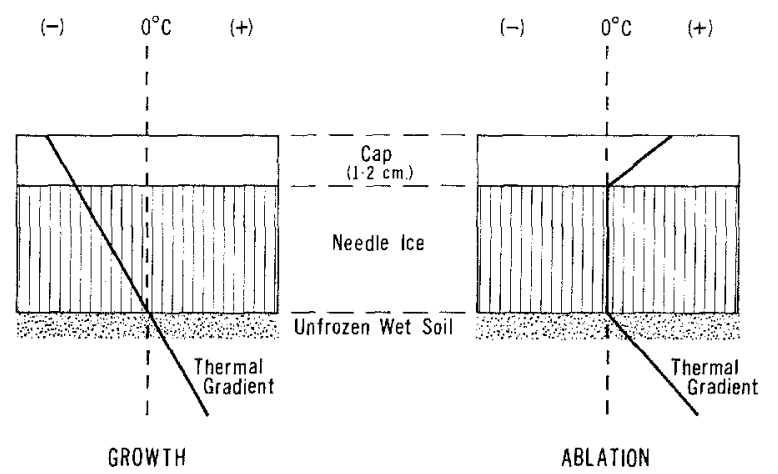

Fig. 1. The Thermal Structures Assigned to Growth and Ablation

the general model specific to the needle ice case) was constructed using the information derived from the U. B. C. studies $[7,8,10]$ (see Table 1).

\section{The Simulation Process}

The digital computer simulation of surface climate is activated by the acquisition of sixteen boundary conditions (i. e. latitude, solar declination, atmospheric dust content, station pressure, orbital radius vector, surface albedo, precipitable water, sky radiation temperature, mean diurnal temperature, air saturation fraction $(R H / 100)$, mean diurnal air wind velocity, soil thermal diffusivity, soil volumetric heat capacity, aerodynamic surface roughness length, soil wet fraction and shadow ratio).

The incoming solar radiation is then calculated as a function of latitude, precipitable water, albedo, station pressure, dust content, orbital radius vector and solar declination at 15 minute increments $[2,9]$. The soil and atmospheric diurnal damping depths are then calculated [9]. In addition, an adiabatic atmospheric exchange coefficient is computed which is later adjusted for stability [5, 9].

Each of the four components of energy transfer (i. e. net radiation, soil heat flux, sensible heat flux and latent heat flux) is a function of varied combinations of the sixteen boundary conditions in addi- 
Table 1. Process-Information Listing

Process Information

Onset of Growth

During Growth

Onset of Ablation

Heave

Thermal Properties of Needle Ice
The surface temperature must descend below $-I^{0} \mathrm{C}$ (Nuc. temp.).

The temperature of the needie bases is $0^{\circ} \mathrm{C}$ (the ice point) and the thermal gradient through the needles and the normally frozen soil cap $(1-2 \mathrm{~cm}$ thick) is determined by the equilibrium temperature solution at the soil surface (cap top).

When the post-nucleation equilibrium temperature solution is greater than the ice point, the ablation branch is used. During this period it is assumed, that the temperature at the base and top of the needles is at the ice point. Thus, the needles are melting from both above and below. During this period the soil heat flux is computed as occurring through the soil cap, having roughly the same thermal properties as the underlying soil. The ablation and growth thermal structures are compared in Fig. 1.

The energy expended on growth (fusion) and melting (ablation) was used to calculate the heave of the soil surface based on the knowledge that the needle density was in the realm of $.2 \mathrm{~g} / \mathrm{cm}^{3}$. When the surface solution was below the ice point, the energy expended on cooling or warming the soil cap-needle mass was subtracted from the soil heat flux to determine incremental heave.

As the "density realm" of needle ice (@.2) was known, the thermal conductivity of the needle-cap can be estimated by weighting the thermal properties of the cap and needles using heave elevation. Thus, the soil heat during the growth-melt cycle is a time dependent function of both heave elevation and the equilibrium temperature solution at each iteration. The uppermost soil substrate temperature is set at the ice point when needles where present and the other substrate temperatures are determined by finite difference solutions of the Fickian diffusion equation at each iteration.

The Exit
The needle ice generator (and destruction) path of the programme was exited when the accumulated heave reached zero. After this "trigger point" is reached in the programme the needle generator-destruction path will not be reentered until the equilibrium temperature solution descends below the "nucleation trigger" value of $-1^{0} \mathrm{C}$.

tion to surface temperature $[5,9]$. An interval-halving process substitutes surfaces temperatures into this system of equations until the residual in the sum of the energy exchange components has an absolute value of less than $1 \mathrm{mly} / \mathrm{min}$. When this condition exists the values of the energy exchange components and surface temperature are retained for that time (iteration). This process is repeated at 15 minute intervals (96/diurnal cycle). The solution surface temper- 
ature is called the equilibrium surface temperature and is that surface temperature which will balance the energy transfer equation at a specific time.

Lag in the surface temperature regime (lagging solar incoming radiation) is produced mainly by the solution of the Fickian diffusion equation at four substrate soil levels between the diurnal damping depth and the surface. In the needle ice case the thermal effects and requirements of ice nucleation, and needle growth-melt in addition to thermally driven soil water flow are incorporated into the simulator. A typical set of output data is included as an appendix.

The boundary conditions listed in the appendix example are considered standard conditions and were selected from field and laboratory studies [7]. It should be noted that the radiation generator employed in the simulator is only applicable to clear weather situations, providing a symmetrical and continuous forcing function. However, fortunately, needle ice is a clear weather phenomena. The specific boundary conditions for the simulation considered here were selected to approximate the environmental conditions during an 11 day sequence of serial needle ice growth-ablation events which occurred at Vancouver, Canada commencing on February 6, 1968 [8].

\section{The Simulator Output}

The simulator output is composed of hourly estimates of heave, net radiation, soil heat flux, sensible heat flux, latent heat flux and surface temperature. The mean hourly temperature curve, derived

Table 2. Comparison of Simulation with Eleven Day Means

\begin{tabular}{cccccr}
\hline $\begin{array}{c}\text { Time } \\
\text { (Solar Time) }\end{array}$ & $\begin{array}{c}\text { Heave } \\
(\mathrm{mm})\end{array}$ & $\begin{array}{c}\text { Net Radiation } \\
\text { (mly.min) }\end{array}$ & $\begin{array}{c}\text { Time } \\
\text { (Solar Time) }\end{array}$ & $\begin{array}{c}\text { Heave } \\
\text { (mm) }\end{array}$ & $\begin{array}{c}\text { Net Radiation } \\
\text { (mly. } / \mathrm{min})\end{array}$ \\
\hline & & & & & \\
0000 & $4(0.5)$ & $-111(-81)$ & 1200 & $0(0.0)$ & $357(354)$ \\
0100 & $7(1.3)$ & $-110(-83)$ & 1300 & $0(0.0)$ & $317(332)$ \\
0200 & $10(2.2)$ & $-107(-82)$ & 1400 & $0(0.0)$ & $227(304)$ \\
0300 & $13(3.2)$ & $-108(-82)$ & 1500 & $0(0.0)$ & $97(135)$ \\
0400 & $15(4.5)$ & $-107(-77)$ & 1600 & $0(0.0)$ & $-53(-10)$ \\
0500 & $18(5.8)$ & $-106(-75)$ & 1700 & $0(0.0)$ & $-132(-95)$ \\
0600 & $21(6.8)$ & $-105(-69)$ & 1800 & $0(0.0)$ & $-125(-97)$ \\
0700 & $23(7.9)$ & $-104(-73)$ & 1900 & $0(0.0)$ & $-121(-91)$ \\
0800 & $25(8.7)$ & $-21(-20)$ & 2000 & $0(0.0)$ & $-118(-86)$ \\
0900 & $22(8.7)$ & $144(103)$ & 2100 & $0(0.0)$ & $-116(-88)$ \\
1000 & $14(5.8)$ & $277(228)$ & 2200 & $0(0.0)$ & $-114(-83)$ \\
1100 & $1(0.4)$ & $366(296)$ & 2300 & $0(0.0)$ & $-113(-83)$
\end{tabular}

( ) field values 
from field data, is compared with the output from the general surface climate simulator (homogeneous soil), the output from a simulator with fusion effects included (freezing and heave) and the needle ice case simulator (which incorporates both fusion and water flow effects) in Fig. 2. The simulator output is compared with eleven day field means in Table 2 for heave and net radiation.

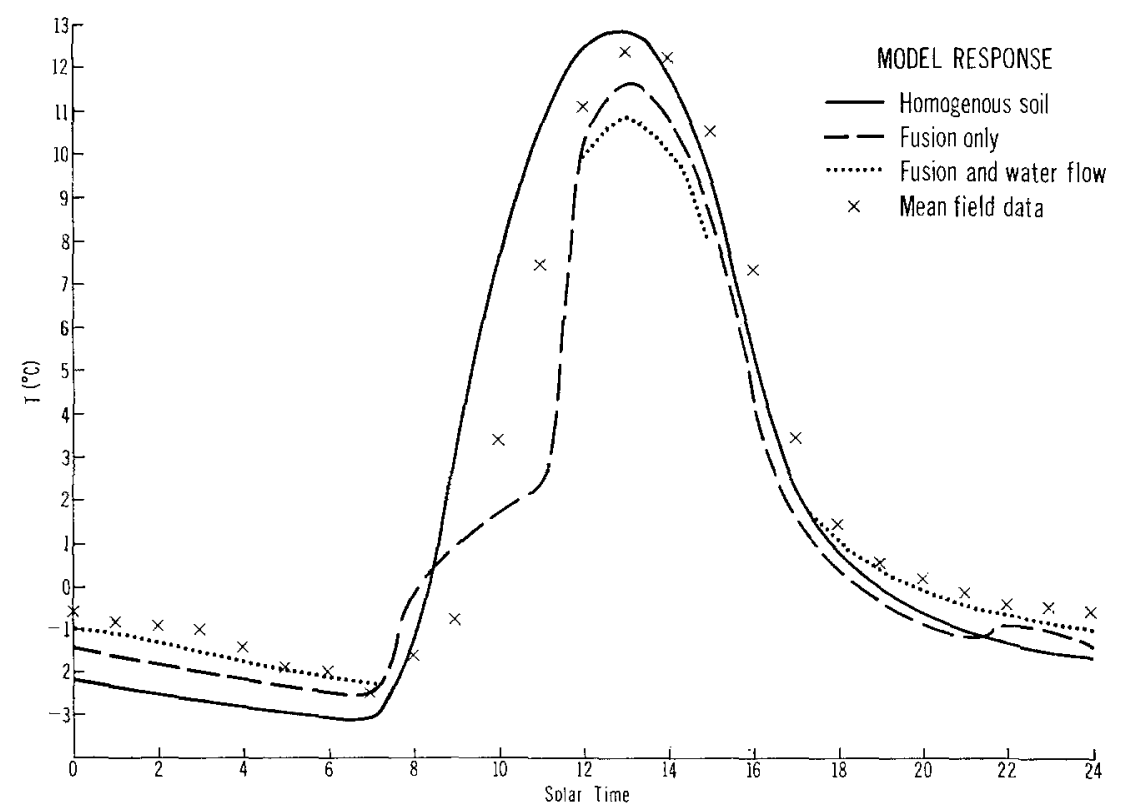

Fig. 2. The Thermal Output of Three Simulation Models Compared to Field Data

The simulator estimates of the values of energy exchange components under nocturnal conditions can be compared with values calculated from field measurements employing Bowen ratio theory and soil heat flux discs on the night of February 16-17, 1968 [7].

\section{Critique of Needle Ice Simulator}

Although needle ice with a maximum length of $2 \mathrm{~cm}$ was observed at sites in the test area, the heave beneath the heave meter used in the field experimental programme never reached this value. However, the correlation between simulated values and the mean field values when time dependence and reliate magnitude are examined was extremely encouraging (see Fig. 3). 
The nocturnal energy transfer environment (see Table 3) appeared to be faithfully duplicated and there is no reason to believe that the "simulator error halo" is larger than the "field measurement error

Table 3. Nocturnal Energy Transfer, February 16-17, 1968

\begin{tabular}{ccccc}
\hline $\begin{array}{l}\text { Time } \\
\text { (PST) }\end{array}$ & $\begin{array}{c}\text { Net Radiation } \\
\text { (mly./min) }\end{array}$ & $\begin{array}{c}\text { Sensible Heat } \\
\text { (mly./min) }\end{array}$ & $\begin{array}{c}\text { Latent Heat } \\
\text { (mly./min) }\end{array}$ & $\begin{array}{c}\text { Soil Heat } \\
\text { (mly/min) }\end{array}$ \\
\hline 2000 & $-116(-88)$ & $39(26)$ & $-8(-12)$ & $84(74)$ \\
2200 & $-112(-88)$ & $42(45)$ & $-5(-5)$ & $75(48)$ \\
0000 & $-111(-88)$ & $42(51)$ & $-4(-17)$ & $73(54)$ \\
0200 & $-109(-79)$ & $43(43)$ & $-3(12)$ & $68(24)$ \\
0400 & $-107(-62)$ & $44(24)$ & $-2(-2)$ & $64(40)$ \\
0600 & $-105(-72)$ & $45(68)$ & $-1(-22)$ & $61(26)$ \\
( ) field values & & &
\end{tabular}

halo". More specifically, as a soil heat flux disc, net radiameter, aspirated psychrometer, and surface thermistor were used in the field measurement programme a large portion of the discrepency may be due to soil heat flux divergence near the surface and water flow effects producing erroneous soil heat measurements. This hypothesis is

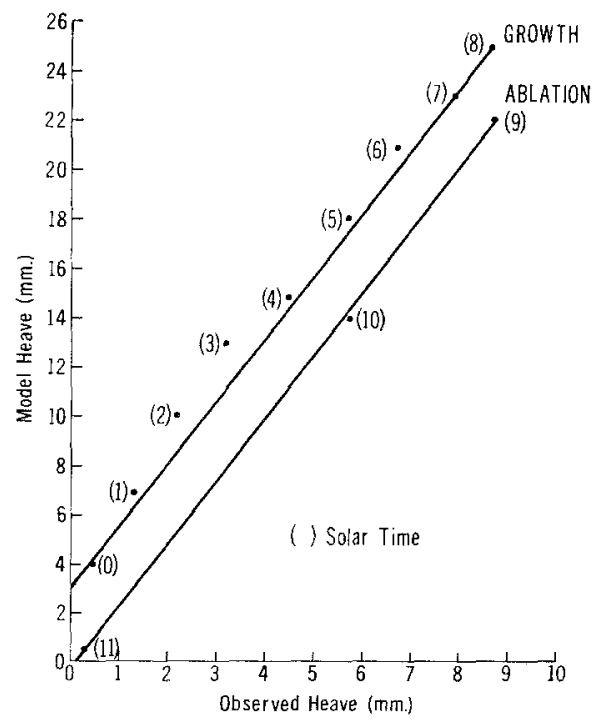

Fig. 3. The Comparison of Simulated Heave with Field Data

further strengthened as it may be noted that field and simulator Bowen ratio (sensible/latent heat ratio) values are similar. In conclusion, although the simulator-field convergence is not ideal, the energy transfer and heave output functions appear to be well within 
the "error halo" of the field measurement-analysis system. Further, surface temperature and soil heave are quite probably responding in fine detail to time dependent processes which vary about the simulation boundary values or have not been included in the model. However, the gross features of the needle ice growth-melt system have been duplicated to a degree which is satisfying to this author.

\section{Sensitivity Testing}

If one accepts the hypothesis that the gross environment of a needle ice event is adequately simulated by the model described above, it is then possible to perform "experiments" of a type denied to climatologists due to the historical nature of their data. In other words, one can examine the sensitivity of the response of a model output function (e. g. soil heave) to the variation of one or a group of model boundary conditions within their observed or probable range [5]. This type of simulation-sensitivity experiment represents an approach to the controlled experimental environment enjoyed by the "pure" sciences and appears particularly useful as mankind becomes increasingly inquisitive in the area of environmental manipulation toward a pre-determined "desirable state", especially in the world's expanding urban areas [5].

It should be stressed that sensitivity testing is best carried out over boundary condition ranges which correspond to observed or predicted ranges and in combinations where physically realistic correlations between boundary conditions are preserved. Some examples are presented below.

\section{Meteorological Sensitivity}

It was found using the standard boundary conditions that needle growth was terminated as the mean wind velocity approached

Table 4. Meteorological Sensitivity Testing for Max. Needle Length (mm)

\begin{tabular}{cccc}
\hline $\begin{array}{c}\text { Wind } \\
\mathrm{cm} / \mathrm{sec}\end{array}$ & $40 \%$ & $\begin{array}{c}\mathrm{RH} \\
50 \%\end{array}$ & $60 \%$ \\
\hline 80 & 43 & 42 & 40 \\
120 & 32 & 27 & 18 \\
160 & 23 & 10 & 0
\end{tabular}

$180 \mathrm{~cm} / \mathrm{sec}$ due largely to the increased time necessary for cooling to the nucleation temperature during a finite nocturnal period. Fur- 
ther, as the atmosphere becomes damper, there was a slight reduction in maximum needle height. These results are presented in Table 4.

Lastly, the analysis indicated that optimum needle growth would occur at a wind velocity in the realm of $80 \mathrm{~cm} / \mathrm{sec}$ under the standard boundary condition. These conditions are in agreement with observations and a study of the significance of meteorological variable differences between needle ice events and other nights during the winter season at Vancouver [7] which indicated that the growth environment was unfavorable when the wind velocity at the $2 \mathrm{ft}$ level exceeded $150 \mathrm{~cm} / \mathrm{sec}$.

\section{Geographical Sensitivity}

Geographical factors are those boundary conditions which are characteristics of the surface and thus most liable to human manipulation in a passive sense (i. e. the manipulation is directed to some other goal than climate modification which in this sense would be considered active). Tests indicated that maximum diurnal needle height decreased with the aerodynamic surface roughness length of the surface in the following manner:

Table 5. Roughness Length and Needle Height

\begin{tabular}{lcccc}
\hline Roughness Length $(\mathrm{cm}) \ldots \ldots \ldots \ldots$ & 2. & 4. & 6. & 8. \\
Max. Needle Height $(\mathrm{mm}) \ldots \ldots \ldots$ & 27 & 19 & 11 & 6
\end{tabular}

These results indicate that plowing the field and roughly doubling the ridge relief from its initial value would have a significant effect upon needle growth. Further, it may be inferred that artificial obstruction of air flow may be effective in minimizing the effects of diurnal needle ice damage to crops.

Observations of ice needle morphology at Vancouver, Canada, indicated that needle growth was occurring during the daylight hours along the north side of an east-west fence [7]. Assuming that the fence contained only $80 \%$ vertical slats the beam radiation content was reduced to only $20 \%$ of its computed value, whereas only $60 \%$ of the cold sky would act as a thermal radiation sink. If the mean diurnal temperature is lowered from $7.0^{\circ} \mathrm{C}$ (std. boundary value) to $6.0^{\circ} \mathrm{C}$ diurnal ablation would be incomplete and the refreezing of melt water derived from the incomplete ablation could be responsible for the banded structures described and analyzed by Outcalt $[7,10]$. A further drop in mean diurnal temperature to $5 \cdot 0^{\circ} \mathrm{G}$ would 
trigger continuous needle growth during the hours of daylight, given a suitable supply of soil water. This testing may explain the deep growths of needles observed at wet sites in Vancouver at locations where the southern sky hemisphere was obstructed [7].

\section{Conclusion}

The results of this research may be summarized as follows:

a) The general simulator credibility is strengthened as convergence with field data increased as observed processes were added to the simulator.

b) It is possible to simulate the time dependent geomorphic effects of a climatic-geomorphic process.

c) Analysis of the simulation-sensitivity testing type described and illustrated in this article may prove useful in comparing land-use manipulation schemes and thus has implications far beyond the scope of this paper, which is simply a test of an analysis strategy.

\section{Acknowledgements}

Funds for the data collection and analysis were provided by the National Research Council of Canada and the University of British Columbia through the good offices of Prof. J. Ross Mackay. The simulator was developed using the Michigan Terminal System on a Faculty Computing Grant provided by the University of Michigan. Miss JoAn ENERson, staff cartographer, Department of Geography, drafted the figures used in this article. Lastly, the idea of simulation was first presented to the author by Dr. M. MrYake of the University of British Columbia.

\section{Appendix}

UBC Met, simulation of needle ice event sequence of Feb. 1968

Latitude $=49.3$

Solar declination $=-14.9$

Station pressure $(\mathrm{mb})=1020$

Dust particles $/ \mathrm{CG}=0.2$

Orbital radius vector $=0.98662$

Albedo $=0.15$

Precipitable water $(\mathrm{mm})=7$

Sky radiant temp. $(\mathrm{C})=-20.0$
Mean diurnal air temp. $(\mathrm{C})=7.0$

Air Saturation fraction $=0.50$

Air wind velocity $(\mathrm{cm} / \mathrm{sec})=120$

Soil thermal diffusivity (CGS) $=.0056$

Soil vol. Heat capacity (CGS) $=0.500$

Roughness length $(\mathrm{cm})=2$

Soil wet fraction $=1.00$

Shadow ratio $=0.0$

Soil damping depth $(\mathrm{cm})=54$

Air damping depth $(\mathrm{cm})=1249$

Air heat transfer coef. (CGS) $=0.00046$ 


\begin{tabular}{rccccc}
\hline $\begin{array}{c}\text { Time } \\
\text { Sun) }\end{array}$ & Ex. Terra. & $\begin{array}{c}\text { Bean } \\
(\text { All mly } / \mathrm{min})\end{array}$ & Back Sct. & Total \\
\hline & & & & & \\
8.00 & 247. & 100. & 15. & 1. & 116. \\
9.00 & 515. & 301. & 17. & 2. & 320. \\
10.00 & 821. & 473. & 18. & 2. & 492. \\
11.00 & 850. & 584. & 18. & 2. & 604. \\
12.00 & 894. & 622. & 18. & 2. & 642. \\
13.00 & 850. & 584. & 18. & 2. & 604. \\
14.00 & 721. & 473. & 18. & 2. & 492. \\
15.00 & 515. & 301. & 17. & 2. & 320. \\
16.00 & 247. & 100. & 15. & 1. & 116. \\
& & & & &
\end{tabular}

\begin{tabular}{lccccc}
\hline Solar Time & $\begin{array}{c}\text { Heave } \\
\text { (mm) }\end{array}$ & $\begin{array}{c}R N \\
\text { (All mly./min) }\end{array}$ & $H$ & $L E$ & $T$ \\
& & & (C.) \\
\hline
\end{tabular}

$\begin{array}{rrrrrrr}12.00 & 0 . & 356 . & -252 . & -21 . & -84 . & 10.1 \\ 13.00 & 0 . & 318 . & -198 . & -27 . & -93 . & 10.8 \\ 14.00 & 0 . & 229 . & -125 . & -21 . & -84 . & 10.1 \\ 15.00 & 0 . & 99 . & -32 . & -5 . & -61 . & 7.9 \\ 16.00 & 0 . & -51 . & 68 . & 16 . & -34 . & 4.5 \\ 17.00 & 0 . & -130 . & 116 . & 31 . & -17 . & 1.6 \\ 18.00 & 0 . & -123 . & 100 . & 35 . & -12 . & 0.7 \\ 19.00 & 0 . & -119 . & 91 . & 38 . & -10 . & 0.0 \\ 20.00 & 0 . & -116 . & 84 . & 39 . & -8 . & -0.4 \\ 21.00 & 0 . & -114 . & 79 . & 41 . & -6 . & -0.8 \\ 22.00 & 0 . & -112 . & 75 . & 42 . & -5 . & -1.0 \\ 23.00 & 1 . & -113 . & 76 . & 41 . & -5 . & -1.0 \\ 0.00 & 4 . & -111 . & 73 . & 42 . & -4 . & -1.2 \\ 1.00 & 7 . & -110 . & 71 . & 43 . & -4 . & -1.4 \\ 2.00 & 10 . & -109 . & 68 . & 43 . & -3 . & -1.5 \\ 3.00 & 13 . & -108 . & 67 . & 44 . & -2 . & -1.7 \\ 4.00 & 15 . & -107 . & 64 . & 44 . & -2 . & -1.9 \\ 5.00 & 18 . & -106 . & 62 . & 45 . & -1 . & -2.0 \\ 6.00 & 21 . & -105 . & 61 . & 45 . & -1 . & -2.2 \\ 7.00 & 23 . & -104 . & 58 . & 45 . & -0 . & -2.3 \\ 8.00 & 25 . & -21 . & -7 . & 38 . & -10 . & 0.1 \\ 9.00 & 22 . & 141 . & -153 . & 30 . & -18 . & 1.8 \\ 10.00 & 14 . & 277 . & -275 . & 23 . & -26 . & 3.3 \\ 11.00 & 1 . & 366 . & -353 . & 18 . & -32 . & 4.2 \\ 12.00 & 0 . & 357 . & -252 . & -21 . & -83 . & 10.1 \\ 13.00 & 0 . & 317 . & -195 . & -28 . & -94 . & 11.0 \\ 14.00 & 0 . & 227 . & -119 . & -23 . & -86 . & 10.3 \\ 15.00 & 0 . & 97 . & -27 . & -7 . & -63 . & 8.1 \\ 16.00 & 0 . & -53 . & 74 . & 15 . & -36 . & 4.8 \\ 17.00 & 0 . & -132 . & 121 . & 30 . & -18 . & 1.9 \\ 18.00 & 0 . & -125 . & 106 . & 34 . & -14 . & 1.0 \\ 19.00 & 0 . & -121 . & 96 . & 37 . & -11 . & 0.4 \\ 20.00 & 0 . & -118 . & 90 . & 38 . & -9 . & -0.1 \\ 21.00 & 0 . & -116 . & 84 . & 40 . & -7 . & -0.4 \\ 22.00 & 0 . & -114 . & 80 . & 40 . & -6 . & -0.7 \\ 23.00 & 0 . & -113 . & 77 . & 41 . & -5 . & -0.9\end{array}$


Soil Temperature Matrix

\begin{tabular}{|c|c|c|c|c|c|}
\hline Depth Time $(\mathrm{cm})$ & 0. & 3. & 7. & 13. & 27. \\
\hline 12.00 & 10.1 & 5.1 & 3.5 & 1.9 & 2.6 \\
\hline 13.00 & 10.8 & 6.9 & 5.4 & 2.8 & 3.0 \\
\hline 14.00 & 10.1 & 7.6 & 6.4 & 3.7 & 3.3 \\
\hline 15.00 & 7.9 & 7.2 & 6.5 & 4.2 & 3.6 \\
\hline 16.00 & 4.5 & 5.9 & 5.8 & 4.4 & 3.7 \\
\hline 17.00 & 1.6 & 3.9 & 4.4 & 4.2 & 3.8 \\
\hline 18.00 & 0.7 & 2.7 & 3.3 & 3.9 & 3.8 \\
\hline 19.00 & 0.0 & 1.8 & 2.5 & 3.5 & 3.8 \\
\hline 20.00 & -0.4 & 1.3 & 1.9 & 3.2 & 3.8 \\
\hline 21.00 & -0.8 & 0.8 & 1.5 & 2.8 & 3.8 \\
\hline 22.00 & -1.0 & 0.5 & 1.1 & 2.6 & 3.7 \\
\hline 23.00 & -1.0 & 0.0 & 1.0 & 2.3 & 3.7 \\
\hline 0.00 & -1.2 & 0.0 & 1.1 & 2.2 & 3.7 \\
\hline 1.00 & -1.4 & 0.0 & 1.1 & 2.2 & 3.7 \\
\hline 2.00 & -1.5 & 0.0 & 1.1 & 2.1 & 3.7 \\
\hline 3.00 & -1.7 & 0.0 & 1.0 & 2.0 & 3.7 \\
\hline 4.00 & -1.9 & 0.0 & 1.0 & 2.0 & 3.6 \\
\hline 5.00 & -2.0 & 0.0 & 1.0 & 2.0 & 3.6 \\
\hline 6.00 & -2.2 & 0.0 & 1.0 & 1.9 & 3.6 \\
\hline 7.00 & -2.3 & 0.0 & 1.0 & 1.9 & 3.6 \\
\hline 8.00 & 0.1 & 0.0 & 1.0 & 1.9 & 3.6 \\
\hline 9.00 & 1.8 & 0.0 & 0.9 & 1.9 & 3.6 \\
\hline 10.00 & 3.3 & 0.0 & 0.9 & 1.9 & 3.6 \\
\hline 11.00 & 4.2 & 0.0 & 0.9 & 1.8 & 3.6 \\
\hline 12.00 & 10.1 & 5.0 & 3.6 & 2.6 & 3.8 \\
\hline 13.00 & 11.0 & 7.1 & 5.6 & 3.6 & 4.1 \\
\hline 14.00 & 10.3 & 7.9 & 6.7 & 4.4 & 4.3 \\
\hline 15.00 & 8.1 & 7.6 & 6.9 & 4.9 & 4.5 \\
\hline 16.00 & 4.8 & 6.3 & 6.2 & 5.1 & 4.7 \\
\hline 17.00 & 1.9 & 4.4 & 4.9 & 4.9 & 4.7 \\
\hline 18.00 & 1.0 & 3.1 & 3.8 & 4.5 & 4.7 \\
\hline 19.00 & 0.4 & 2.3 & 3.0 & 4.1 & 4.6 \\
\hline 20.00 & -0.1 & 1.7 & 2.4 & 3.8 & 4.6 \\
\hline 21.00 & -0.4 & 1.3 & 2.0 & 3.5 & 4.5 \\
\hline 22.00 & -0.7 & 0.9 & 1.6 & 3.2 & 4.4 \\
\hline 33.00 & -0.9 & 0.6 & 1.3 & 2.9 & 4.4 \\
\hline
\end{tabular}

\section{References}

1. Brink, V. C., J. R. Mackay, S. Freyman, and D. G. Pearce: Needle Ice and Seedling Establishment in Southwestern British Columbia. Canadian Journal Plant Science 47, 135-139 (1967).

2. Gates, D. M.: Energy Exchange in the Biosphere. Harper \& Row Biological Monographs, 151 pp. (1962).

3. Lettau, H.: Evaporation Climatonomy. Mo. Wea. Review 97, 691-699 (1969).

4. Lonngvist, O.: On Diurnal Variation of Surface Temperature. Tellus XIV, 96-101 (1962).

5. Mrrup, L. O.: A Numerical Model of the Urban Heat Island. Jour. App. Met. 8, 908-918 (1969). 
6. Outcalt, S. I.: Weather and Diurnal Frozen Soil Structure at Charlottesville, Virgina. Water Resources Research 5, 1377-1381 (1969).

7. Outcalt, S. I.: A Study of Needle Ice Events at Vancouver, Canada. Dissertation, University of British Columbia, Vancouver (1970).

8. Outcalt, S. I.: A Study of Time Dependence During Serial Needle Ice Events. Arch. Met. Geoph. Biokl., A, 19, 329-337 (1970).

9. Outcalt, S. I.: A Numerical Surface Climate Simulator. Geographical Analysis (in press).

10. Outcalt, S. I.: Field Observations of Soil Temperature and Water Tension Feedback Effects on Needle Ice Nights. Arch. Met. Geoph. Biokl. A, 20, $43-53$ (1971).

Author's address: Dr. Sam I. Outcalt, The University of Michigan, Department of Geography, Ann Arbor, M/48104, U. S. A. 